\title{
Erst einmal eine Auszeit nehmen und sich beraten lassen!
}

Als ich im Januar 2018 nach Potsdam zog, war ich hoch motiviert: Mein Studium hatte ich erfolgreich beendet und nun musste ich nur noch die letzte Hürde überwinden, um meinen Traumberuf Grundschullehrerin zu erreichen: das Referendariat. Fünf Tage hat es gedauert, bis sich mein Leben ändern sollte. In meinem WG-Zimmer voller Umzugskartons ertastete ich eines Abends eine Verhärtung in meiner Brust. Zwei Tage später hatte ich einen Termin bei einem Gynäkologen. Im Ultraschall sah man einen Tumor von etwa 1,5 cm Größe, der abgeklärt werden musste. „Machen Sie sich keine großen Sorgen. Ich hatte noch nie eine Patientin in ihrem Alter, bei der es etwas Bösartiges war.“ Mit diesen Worten verabschiedetet mich der Mediziner.

Zwei Wochen, fünf Tage im Referendariat und eine Biopsie später, betrat ich das Büro der Chefärztin des Brustzentrums in Potsdam und erfuhr, dass ich an triple negativem Brustkrebs erkrankt war und mich damit die gesamte Behandlung erwartet - Chemotherapie, OP, Bestrahlung. Mit 25 Jahren.

Aufgrund der Infektionsgefahr durfte ich nicht mehr in die Schule gehen. Dennoch wägte ich mich in Sicherheit, schließlich trug ich seit wenigen Wochen den Titel „Beamtin auf Widerruf“ und als Beamtin erhält man seine Bezüge selbst im Krankheitsfall dauerhaft. Am nächsten Morgen sprach ich direkt mit meiner Sachbearbeiterin im Ministerium für Bildung, Jugend und Sport und erklärte ihr meine Situation. Trotz großer Betroffenheit gab sie mir zu verstehen, dass ich meinen Platz im Referendariat freiwillig zurückgeben müsse, sonst hätte ich nicht die Möglichkeit, in Brandenburg erneut einzusteigen, sobald ich wieder genesen sei. Ich war überfordert, wusste nicht, an wen ich mich hätte wenden sollen und gab schließlich meinen Platz zurück. Im Nachhinein kann ich nur raten, sich erstmal eine Zeit krankschreiben zu lassen (vielleicht zwei Wochen), sich in der Zeit zu sammeln und Beratungsstellen aufzusuchen, um über seine Rechte besser informiert zu sein. Denn mit Unterstützung lässt sich solch eine Zeit besser meistern. Auch der Austausch mit anderen Betroffenen, beispielsweise in den TREFFPUNKTEN der Deutschen Stiftung für junge Erwachsene mit Krebs, bringt oft Klarheit in den Schwall von Informationen.

Für mich war die Konsequenz der Gang zum Jobcenter und der Antrag auf ALG II, also Hartz IV. Unter Tränen erklärte ich der Sachbearbeiterin meine Situation, wodurch ich auch hier zwar auf Mitgefühl traf, doch am Ende erwarteten mich dieselben Regelungen wie für jeden anderen Erwerbslosen. Abgesehen da-

Ә OpenAccess. (c) 2021 Katharina Luise Meier, publiziert von De Gruyter. (cc)BY-NC-SA Dieses Werk ist lizenziert unter einer Creative Commons Namensnennung - Nicht kommerziell - Weitergabe unter gleichen Bedingungen 4.0 International Lizenz. https://doi.org/10.1515/9783110713336-038 
von, dass das Jobcenter eigentlich nur für erwerbsfähige Menschen zuständig ist, was man als Krebspatient de facto nicht ist, waren das Ausfüllen des Antrages und die damit verbundenen bürokratischen Hürden eine extreme Belastung. Ich stand immer noch unter Schock von der Diagnose und durchlebte gerade den Beginn meiner Chemotherapie, inklusive erster Nebenwirkungen.

Während meine Freunde ihren ersten Jobs nachgingen, am Wochenende feierten oder ihren nächsten Urlaub planten, war ich nicht nur körperlich zu geschwächt, sondern mir fehlten auch die finanziellen Mittel. Nach Abzug aller Nebenkosten, Versicherungen etc., blieben mir im Monat ca. $129 €$ zum Leben. Ich war in der Armut angelangt, obwohl ich doch noch kurz zuvor auf einem ganz anderen Weg war.

Mein Behandlungsteam konnte sich meist ebenfalls nur schwer vorstellen, welche Konsequenzen eine solche finanzielle Situation hat. So sollte ich laut Ernährungstherapeutin möglichst nur noch Bioprodukte essen. Außerdem bewirkten die Medikamente eine schnelle Gewichtszunahme, wodurch ich alle paar Wochen neue Kleidung brauchte. Meine Ärzte empfahlen mir immer wieder, einen kleinen Urlaub zu machen, insbesondere für meine Psyche. In jeder Situation fragte ich mich: Von welchem Geld? Ich fühlte mich oft so unverstanden und wusste nicht, an wen ich mich wenden sollte. Erst nach der eigentlichen Therapie erfuhr ich in der Anschlussheilbehandlung von einem Krebshärtefonds der Deutschen Krebsgesellschaft, über den ich immerhin eine Einmalzahlung erhielt, die mich zumindest kurzzeitig etwas entlastete.

Eine andere Betroffene sagte einmal: Wenn ich finanzielle Sorgen habe, kann ich nicht gesund werden. Dem stimme ich zu. Es belastet die Psyche ungemein und eine belastete Psyche erschwert oft einen Genesungsprozess.

Nachdem das Jobcenter mir Anfang 2019 mitteilte, dass sie meine vollen Mietkosten nur noch bis September 2019 übernähmen, war ich dazu gezwungen, im August 2019 das Referendariat neu aufzunehmen. Als ALG-II-Empfänger hatte ich keinen Anspruch auf eine Wiedereingliederung und musste daher mit dem vollen Pensum einsteigen. Dies machte sich bereits einen Monat später durch immer häufiger auftretende Panikattacken und Erschöpfung bemerkbar. Es folgte eine neue langfristige Krankschreibung. Mit einem Unterschied: Diesmal war ich über meine Rechte aufgeklärter und suchte mir Unterstützung im Studienseminar, sodass ich meinen Beamtenstatus behalten durfte und somit finanziell abgesichert bin. Diese Gewissheit hilft mir nun, dass ich das Geschehene aufarbeiten und mich auf meine Rückkehr ins Referendariat im Sommer 2020 vorbereiten kann. 